\title{
РОЛЬ ВЫСШЕГО ПРОФЕССИОНАЛЬНОГО ОБРАЗОВАНИЯ В ОБЕСПЕЧЕНИИ ДОЛГОСРОЧНОЙ ЭКОНОМИЧЕСКОЙ БЕЗОПАСНОСТИ РОССИЙСКОЙ ФЕДЕРАЦИИ
}

\author{
(c) 2019 Николаева Елена Анатольевна
}

кандидат социологических наук, доцент кафедры иностранных языков № 3 Российский экономический университет им. Г.В. Плеханова, Россия, Москва E-mail: yoltash82@mail.ru

(c) 2019 Строганов Игорь Алексеевич

кандидат экономических наук, доцент кафедры предпринимательства и логистики Российский экономический университет им. Г.В. Плеханова, Россия, Москва E-mail: stroganov.ia@rea.ru

\section{(c) 2019 Строганова Ирина Игоревна}

старший преподаватель кафедры иностранных языков № 3

Российский экономический университет им. Г.В. Плеханова, Россия, Москва

E-mail: Stroganova.II@rea.ru

(c) 2019 Адасова Яна Борисовна

преподаватель кафедры иностранных языков № 3

Российский экономический университет им. Г.В. Плеханова, Россия, Москва

E-mail: adasova_yana@rambler.ru

В статье авторов рассматривается вопрос роли высшего профессионального образования в обеспечении долгосрочной экономической безопасности Российской Федерации. Объектом исследования выступила экономическая безопасность Российской Федерации, а предметом - высшее профессиональное образование и его функциональная значимость. Теоретическое и методологическое значения исследования заключены в развитии теории функциональной нагрузки экономических категорий в разрезе корреляционной интеграции с процессным аспектом экономической безопасности. Практическое значение исследования определяется количественной формализацией функциональной нагрузки исследуемой экономической категории в аспекте повышения экономической безопасности Российской Федерации.

Ключевые слова: Высшее профессиональное образование, экономическая безопасность, Российская Федерация, функции, обеспечение.

Обеспечение экономической безопасности государства является одной из самых приоритетных задач для всех без исключения стран в мировой экономической формации [1, с. 224]. Именно поэтому в исследование данного процесса как в теоретической, так и практической плоскости на мировой арене [7] инвестируются значительные суммы денежных средств $[4,5]$.

Объемы инвестиций в исследование вопроса обеспечения экономической безопасности государства некоторыми странами в 2018 году приведены в таблице 1 [8]. Как можно увидеть, в 2018 году в мире доминировали инвестиции именно в практическую составляющую экономической безопасности (Китай, Германия, Канада и Россия). Далее следовали дифференцированные приоритеты (Япония, Франция) и лишь в США имел место акцент на исследование методологической составляющей вопроса.

Что касается объёмов инвестирования, то в анализируемый период времени лидирующие позиции (локальный объем инвестиций более 100 млн. долларов США) здесь занимали такие страны, как США, Китай, Япония и Германия на них в совокупности приходилось более 880 млн. долларов США. Менее масштабно в анализируемый вопрос (локальный объем инвестиций от 50 до 100 млн. долларов США) инвестировали Франция и Канада, совокупные инвестиции которых составили чуть менее 180 млн. долларов США. Замыкала перечень, анализируемый стран Российская Федерация, на которую приходилось 
Таблица 1. Объемы инвестиций в исследование вопроса обеспечения экономической безопасности государства некоторыми странами в 2018 году [8], в млн. долларов США

\begin{tabular}{|c|c|c|}
\hline Страна & Инвестиции & $\begin{array}{c}\text { Приоритетное направление } \\
\text { инвестирования }\end{array}$ \\
\hline США & 355 & Методологическая база \\
\hline Китай & 231 & Практическая составляющая \\
\hline Япония & 172 & $\begin{array}{c}\text { Дифференцированное } \\
\text { Инвестирование }\end{array}$ \\
\hline Германия & 126 & Практическая составляющая \\
\hline Франция & 98 & $\begin{array}{c}\text { Дифференцированное } \\
\text { Инвестирование }\end{array}$ \\
\hline Канада & 78 & Практическая составляющая \\
\hline Россия & 49 & Практическая составляющая \\
\hline
\end{tabular}

Указанные суммы не включают затраты на непосредственное обеспечение экономической безопасности того или иного государства. Конвертация сумм к единой валюте (доллар США) приведена по состоянию на начало 2019 года (по данным London International Financial Futures Exchange). Округление сумм, представленных в таблице 1, проведено до целых величин

чуть менее 50 млн. долларов США инвестиций.

В Российской Федерации по состоянию на начало 2019 года вопрос обеспечения экономической безопасности [2, 3], к сожалению, является малоизученным. Так по данным рейтингового агентства Эксперт-РА [10] средняя глубина изучения анализируемого вопроса в Российской Федерации составила менее 25\% (рис. 1). При этом источник отмечает, что наименее изученными здесь (в первую очередь в теоретикометодологическом аспекте) являются: сфера высшего профессионального образования и сфера социальных межличностных коммуникаций [10].

Для разрешения выявленной проблемы было проведено детальное исследование роли высшего профессионального образования в целях обеспечения долгосрочной экономической безопасности Российской Федерации.
Исходя из того, что роль экономической категории определяется, в первую очередь, ее функциональной нагрузкой был проведен предметный подетальней анализ следующих функций высшего профессионального образования: финансово-экономическая, социальная, политическая и информационная (таблицы 2-5).

По итогам можно сделать вывод, что роль высшего профессионального образования в обеспечении долгосрочной экономической безопасности Российской Федерации проявляется через совокупность финансово-экономической, социальной, политической и информационной функциональной нагрузки. При этом взаимное влияние указанных объектов системы в современной теории и практике изучено лишь поверхностно.

Для разрешения сложившейся ситуации рекомендуется активизировать комплексное

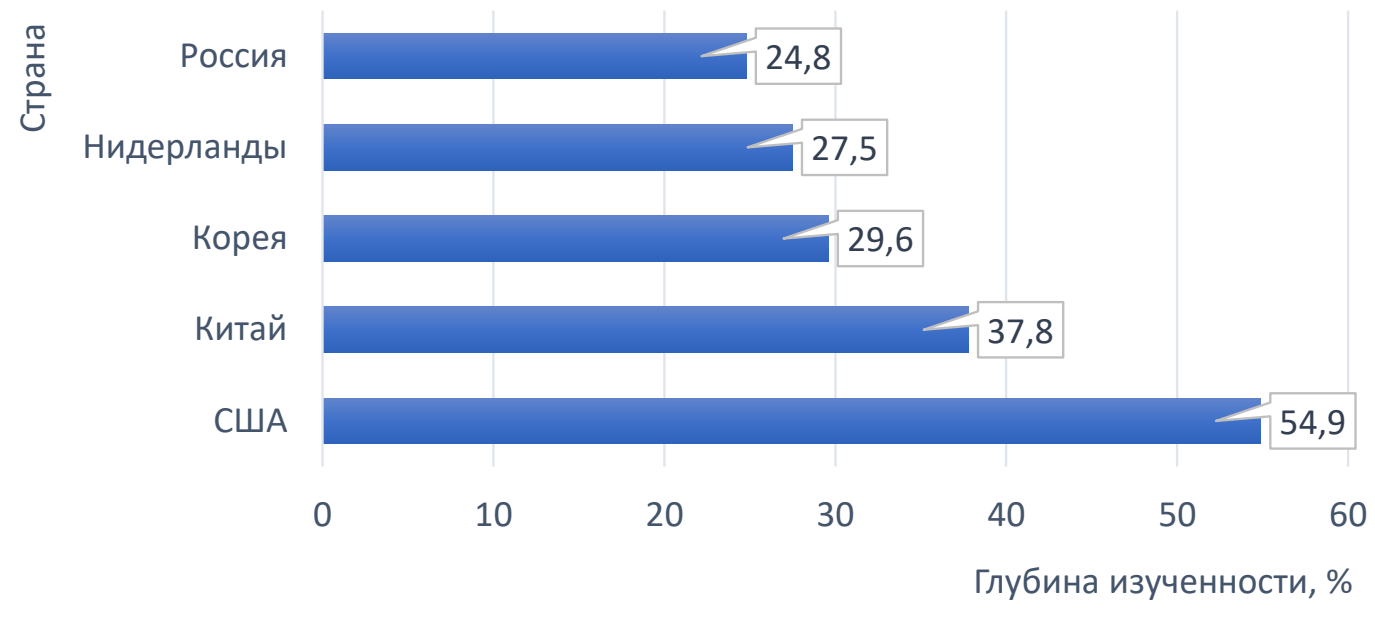

Puc. 1. Средняя глубина изученности вопроса экономической безопасности различных стран на теоретико-практическом уровне [10] 
Таблица 2. Анализ финансово-экономической функции высшего профессионального образования в обеспечении долгосрочной экономической безопасности Российской Федерации

\begin{tabular}{|l|l|l|}
\hline \multicolumn{1}{|c|}{ Элемент функци } & \multicolumn{1}{|c|}{ Содержание элемента } & \multicolumn{1}{|c|}{ Существенные пояснения } \\
\hline Описание & $\begin{array}{l}\text { Реализация финансово- } \\
\text { экономического потенциала } \\
\text { объекта }\end{array}$ & $\begin{array}{l}\text { Потенциал объекта может быть } \\
\text { полностью реализован лишь при } \\
\text { синергетической связи комплекс- } \\
\text { ного функцинала элементов }\end{array}$ \\
\hline $\begin{array}{l}\text { Акценты в долгосрочной перспек- } \\
\text { тиве }\end{array}$ & $\begin{array}{l}\text { Генерация, распределение и } \\
\text { перераспределение финансового } \\
\text { потока }\end{array}$ & $\begin{array}{l}\text { Важно для достижения комплекс- } \\
\text { ной синергии функцинальной } \\
\text { нагрузки }\end{array}$ \\
\hline $\begin{array}{l}\text { Средний уровень теоретической } \\
\text { изученности }\end{array}$ & Порядка 5\% & $\begin{array}{l}\text { Выделенные данные по источнику } \\
\text { «эсперт РА» }\end{array}$ \\
\hline $\begin{array}{l}\text { Средний уровень практической } \\
\text { изученности }\end{array}$ & $\begin{array}{l}\text { Порядка 25\% } \\
\text { «Эсперт РАл данные по источнику }\end{array}$ \\
\hline $\begin{array}{l}\text { Наличие общедоступной статисти- } \\
\text { ческой базы }\end{array}$ & $\begin{array}{l}\text { Присутствует лишь по отдельным } \\
\text { позициям }\end{array}$ & $\begin{array}{l}\text { Объем в достаточной мере ограни- } \\
\text { ченный }\end{array}$ \\
\hline $\begin{array}{l}\text { Потенциал применения в долго- } \\
\text { срочной перспективе }\end{array}$ & $\begin{array}{l}\text { Может быть оценен как очень } \\
\text { высокий }\end{array}$ & $\begin{array}{l}\text { Экспертное мнение авторского } \\
\text { коллектива публикации }\end{array}$ \\
\hline $\begin{array}{l}\text { Уровень комплексной проблемно- } \\
\text { сти элемента }\end{array}$ & Средний & $\begin{array}{l}\text { Экспертное мнение авторского } \\
\text { коллектива публикации }\end{array}$ \\
\hline Рекомендации авторов & $\begin{array}{l}\text { Активизировать комплексное тео- } \\
\text { ретическое изучение элемента }\end{array}$ & $\begin{array}{l}\text { Разработать и формализовать ком- } \\
\text { плекную методологию управле- } \\
\text { ния элементом }\end{array}$ \\
\hline
\end{tabular}

Таблица 3. Анализ социальной функции высшего профессионального образования в обеспечении долгосрочной экономической безопасности Российской Федерации

\begin{tabular}{|c|c|c|}
\hline Элемент функции & Содержание элемента & Существенные пояснения \\
\hline Описание & $\begin{array}{l}\text { Реализация потенциала объекта в } \\
\text { социальной плоскости }\end{array}$ & $\begin{array}{l}\text { Потенциал объекта может быть } \\
\text { полностью реализован лишь при } \\
\text { синергетической связи комплекс- } \\
\text { ного функционала элементов }\end{array}$ \\
\hline $\begin{array}{l}\text { Акценты в долгосрочной перспек- } \\
\text { тиве }\end{array}$ & $\begin{array}{l}\text { Стратегическая оптимизация со- } \\
\text { циальных перспектив }\end{array}$ & $\begin{array}{l}\text { Важно для достижения комплекс- } \\
\text { ной синергии функциональной } \\
\text { нагрузки }\end{array}$ \\
\hline $\begin{array}{l}\text { Средний уровень теоретической } \\
\text { изученности }\end{array}$ & Порядка 3\% & $\begin{array}{l}\text { Выделенные данные по источнику } \\
\text { «Эксперт РА» }\end{array}$ \\
\hline $\begin{array}{l}\text { Средний уровень практической } \\
\text { изученности }\end{array}$ & Порядка 12\% & $\begin{array}{l}\text { Выделенные данные по источнику } \\
\text { «Эксперт РА» }\end{array}$ \\
\hline $\begin{array}{l}\text { Наличие общедоступной статисти- } \\
\text { ческой базы }\end{array}$ & $\begin{array}{l}\text { Присутствует лишь по отдельным } \\
\text { позициям }\end{array}$ & $\begin{array}{l}\text { Объем в достаточной мере ограни- } \\
\text { ченный }\end{array}$ \\
\hline $\begin{array}{l}\text { Потенциал применения в долго- } \\
\text { срочной перспективе }\end{array}$ & Может быть оценен как высокий & $\begin{array}{l}\text { Экспертное мнение авторского } \\
\text { коллектива публикации }\end{array}$ \\
\hline $\begin{array}{l}\text { Уровень комплексной проблемно- } \\
\text { сти элемента }\end{array}$ & Высокий & $\begin{array}{l}\text { Экспертное мнение авторского } \\
\text { коллектива публикации }\end{array}$ \\
\hline Рекомендации авторов & $\begin{array}{l}\text { Активизировать комплексное } \\
\text { теоретико-практическое изучение } \\
\text { элемента }\end{array}$ & $\begin{array}{l}\text { Разработать и формализовать ком- } \\
\text { плексную методологию управле-- } \\
\text { ния элементом }\end{array}$ \\
\hline
\end{tabular}


Таблица 4. Анализ политической функции высшего профессионального образования в обеспечении долгосрочной экономической безопасности Российской Федерации

\begin{tabular}{|l|l|l|}
\hline \multicolumn{1}{|c|}{ Элемент функци } & \multicolumn{1}{|c|}{ Содержание элемента } & \multicolumn{1}{|c|}{ Существенные пояснения } \\
\hline Описание & $\begin{array}{l}\text { Реализация потенциала объекта в } \\
\text { политической плоскости }\end{array}$ & $\begin{array}{l}\text { Потенциал объекта может быть } \\
\text { синергетической связи комплекс- } \\
\text { ного функцинала элементов }\end{array}$ \\
\hline $\begin{array}{l}\text { Акценты в долгосрочной перспек- } \\
\text { тиве }\end{array}$ & $\begin{array}{l}\text { Стратегическая оптимизация по- } \\
\text { литических перспектив }\end{array}$ & $\begin{array}{l}\text { Важно для достижения комплекс- } \\
\text { ной синергии функцональной } \\
\text { нагрузки }\end{array}$ \\
\hline $\begin{array}{l}\text { Средний уровень теоретической } \\
\text { изученности }\end{array}$ & Порядка 6\% & $\begin{array}{l}\text { Выделенные данные по источнику } \\
\text { «эсперт РА» }\end{array}$ \\
\hline $\begin{array}{l}\text { Средний уровень практической } \\
\text { изученности }\end{array}$ & Порядка 8\% & $\begin{array}{l}\text { Выделенные данные по источнику } \\
\text { «эсперт РА» }\end{array}$ \\
\hline $\begin{array}{l}\text { Наличие общедоступной статисти- } \\
\text { ческой базы }\end{array}$ & $\begin{array}{l}\text { Объем в достаточной мере ограни- } \\
\text { ченный }\end{array}$ \\
\hline $\begin{array}{l}\text { Потенциал применения в долго- } \\
\text { срочной перспективе }\end{array}$ & Может быть оценен как высокий & $\begin{array}{l}\text { Экспертное мнение авторского } \\
\text { коллектива публикации }\end{array}$ \\
\hline $\begin{array}{l}\text { Уровень комплексной проблемно- } \\
\text { сти элемента }\end{array}$ & Высокий & $\begin{array}{l}\text { Экспертное мнение авторского } \\
\text { коллектива публикации }\end{array}$ \\
\hline Рекомендации авторов & $\begin{array}{l}\text { Активизировать комплексное } \\
\text { теоретико-практическое изучение } \\
\text { элемента }\end{array}$ & $\begin{array}{l}\text { Разработать и формализовать ком- } \\
\text { плекную методологию управле- } \\
\text { ния элементом }\end{array}$ \\
\hline
\end{tabular}

Таблица 5. Анализ информационной функции высшего профессионального образования в обеспечении долгосрочной экономической безопасности Российской Федерации

\begin{tabular}{|l|l|l|}
\hline \multicolumn{1}{|c|}{ Элемент функци } & \multicolumn{1}{|c|}{ Содержание элемента } & \multicolumn{1}{|c|}{ Существенные пояснения } \\
\hline Описание & $\begin{array}{l}\text { Реализация потенциала объекта в } \\
\text { информационной плоскости }\end{array}$ & $\begin{array}{l}\text { Потенциал объекта может быть } \\
\text { пинергетической сван лишь помплекс- } \\
\text { ного функционала элементов }\end{array}$ \\
\hline $\begin{array}{l}\text { Акценты в долгосрочной перспек- } \\
\text { тиве }\end{array}$ & $\begin{array}{l}\text { Стратегическая оптимизация ин- } \\
\text { формационных перспектив }\end{array}$ & $\begin{array}{l}\text { Важно для достижения комплекс- } \\
\text { ной синергии функцинальной } \\
\text { нагрузки }\end{array}$ \\
\hline $\begin{array}{l}\text { Средний уровень теоретической } \\
\text { изученности }\end{array}$ & Порядка 15\% & $\begin{array}{l}\text { Выделенные данные по источнику } \\
\text { «экперт РА» }\end{array}$ \\
\hline $\begin{array}{l}\text { Средний уровень практической } \\
\text { изученности }\end{array}$ & Порядка 23\% & $\begin{array}{l}\text { Выделенные данные по источнику } \\
\text { «эсперт РА» }\end{array}$ \\
\hline $\begin{array}{l}\text { Наличие общедоступной статисти- } \\
\text { ческой базы }\end{array}$ & Присутствует не в полном объеме & $\begin{array}{l}\text { Объем в достаточной мере ограни- } \\
\text { ченный }\end{array}$ \\
\hline $\begin{array}{l}\text { Потенциал применения в долго- } \\
\text { срочной перспективе }\end{array}$ & Может быть оценен как высокий & $\begin{array}{l}\text { Экспертное мнение авторского } \\
\text { коллектива публикации }\end{array}$ \\
\hline $\begin{array}{l}\text { Уровень комплексной проблемно- } \\
\text { сти элемента }\end{array}$ & Высокий & $\begin{array}{l}\text { Экспертное мнение авторского } \\
\text { коллектива публикации }\end{array}$ \\
\hline Рекомендации авторов & $\begin{array}{l}\text { Активизировать комплексное } \\
\text { теоретико-практическое изучение } \\
\text { элемента }\end{array}$ & $\begin{array}{l}\text { Разработать и формализовать ком- } \\
\text { плекную методологию управле- } \\
\text { ния элементом }\end{array}$ \\
\hline
\end{tabular}


теоретико-практическое изучение элементов системы высшего профессионального образования, уделив при этом особое внимание разработке и формализации комплексной методологии управления.

Результаты исследования, по мере планомерного изучения анализируемого вопроса о взаимном влиянии высшего профессионального образования и экономической безопасности Российской Федерации, проявятся в методологической, методической и практической плоскостях и могут быть планомерно применены для обширного потока теоретико-практических ситуаций.

\section{Библиографический список}

1. Бигжанова А. М., Безверхая О.Н. Угрозы экономической безопасности национальной экономики России: проявления, нейтрализация / А.М. Бигжанова, О.Н. Безверхая // Молодой ученый - Казань: Изд-во «Молодой учёный» - 2018. - № 13. - С. 221-225.

2. Николаева Е. А. и другие Инструменты реализации стратегических инициатив высшего учебного заведения в целях повышения качества образовательного процесса / Е.А. Николаева и другие // Экономические науки - Москва: Изд-во ООО «24-Принт» - 2018. - № 9. - С. 87-90.

3. Николаева E. А., Григорьева И.В. и др. К аспектам влияния оценки эффективности деятельности профессорско-преподавательского состава высшего учебного заведения на укрепление экономической безопасности Российской Федерации / Е.А. Николаева, И.В. Григорьева, И.С. Казимирова, Е.И. Соколова // Экономические науки - Москва: Изд-во ООО «24-Принт», 2019. - № 3.- С. 62-67.

4. Плотников Н.В. Проблемы обеспечения экономической безопасности высшего образования на современном этапе / Н.В. Плотников // Научный журнал НИУ ИТМО. Серия «Экономика и экологический менеджмент» - СПБ: Изд-во «Университет ИТМО» - 2015.— № 3.- С. 143-150.

5. Япаров С. С. Институты обеспечения экономической безопасности в Российской Федерации и направления их совершенствования / С.С. Япаров // Теория и практика сервиса: экономика, социальная сфера, технологии - СПБ: Изд-во Санкт-Петербургский государственный экономический университет - 2016. - № 4.C. $44-50$.

6. Николаева Е.А., Григорьева И.В. и др. К аспектам влияния оценки эффективности деятельности профессорско-преподавательского состава высшего учебного заведения на укрепление экономической безопасности Российской Федерации / Е.А. Николаева, И.В. Григорьева, И.С. Казимирова, Е.И. Соколова // Экономические науки - Москва: Изд-во ООО «24-Принт», 2019. - № 3. - С. 62-67.model. Canadian Journal of Administrative Sciences, Revue Canadienne des Sciences de l'Administration, 28(3), 302-316

7. Spremić, M. (2017): Governing Digital Technology - how Mature IT Governance can help in Digital Transformation? International Journal of Economics and Management Systems, 2, 214-223.

8. World Economics Forum (2018): Global Risk Report 2018.

9. Компания «Делойт Туш Томацу Лимитед» [Электронный ресурс]: аналитические материалы - Официальный сайт компании «Делойт Туш Томацу Лимитед», 2019.- Режим доступа: https://www2.deloitte.com

10. Рейтинговое агентство «Эксперт РА» [Электронный ресурс]: аналитические материалы - Официальный сайт рейтингового агентства «Эксперт РА», 2019.- Режим доступа: https://raexpert.ru 